\title{
INFLUÊNCIA DO MANEJO DA IRRIGAÇÃO E SISTEMA DE CULTIVO NO RENDIMENTO ECONÔMICO DA CULTURA DO FEIJOEIRO IRRIGADA POR PIVÔ CENTRAL
}

\author{
José Eduardo Pitelli Turcoํ, Gilcileia dos Santos Rizzatti², Luiz Carlos Pavani ${ }^{3}$
}

\begin{abstract}
RESUMO
O objetivo deste trabalho foi analisar o consumo e o custo de energia elétrica e o resultado econômico na cultura do feijoeiro, cultivar IAC-Carioca, irrigada por pivô central em um Latossolo Vermelho, submetida a dois manejos de irrigação (tensiometria e tanque "Classe A") e dois sistemas de cultivo (plantio direto e plantio convencional), nos anos de 2003 e 2004. A pesquisa foi desenvolvida na Área Demonstrativa e Experimental de Irrigação - ADEI da FCAV/ UNESP, Câmpus de Jaboticabal - SP, sob um pivô central, que abrange uma área de 33.157,140 m². O consumo de energia elétrica do sistema de irrigação foi monitorado e seu custo analisado para dois grupos tarifários, cujos preços do kWh foram obtidos na CPFL (Companhia Paulista de Força e Luz). O resultado econômico foi obtido subtraindo-se a receita da produtividade do feijão do custo total de produção do feijão, para cada ano estudado. Os tratamentos em que o manejo da irrigação foi realizado pelo método do tanque "Classe A" obtiveram os maiores consumos e custos de energia elétrica, em relação aos tratamentos em que o manejo foi realizado por tensiometria. O maior retorno econômico, devido à maior produtividade, foi observado no tratamento em que o manejo de irrigação foi realizado utilizando-se o tanque "Classe A", e o sistema de plantio adotado foi o convencional, para os dois anos estudados.
\end{abstract}

Palavras-chave: sistemas tarifários, feijão, tensiômetro, tanque "Classe A".

\section{ABSTRACT \\ EFFECT OF IRRIGATION MANAGEMENT AND CULTIVATION SYSTEM ON THE ECONOMIC RETURN OF BEAN CROP IRRIGATED BY CENTRAL PIVOT}

This study was done to analyze the consumption and cost of electric energy and the economical results of bean crop 'IAC-Carioca' grown in Red Latosol (Oxisol) irrigated by central pivot, under irrigation management systems, TENS - tensiometry or TCA - climatological water balance based on "Class A" pan, under no-tillage (NT) or conventional tillage (CT) system, during 2003 and 2004. The study was done in the Demonstrative and Experimental Irrigation Area of FCAV/UNESP, Jaboticabal-SP. The electricity consumption was monitored and its cost was analyzed by tariff groups A and B. The price of Kwh of the tariff was obtained from São Paulo Company of Power and Light. The economical result was calculated by subtracting the income from the total production cost. Irrigation management by the use of TCA method showed higher electricity consumption and cost relative to the management carried out by TENS. The best economical return was found when the irrigation management was carried by the TCA under CT system.

Keywords: tariff systems, bean, tensiometry, "Class A" pan.

\section{Recebido para publicação em 13/10/2010. Aprovado em 27/02/2012.}

1- Engenheiro Eletricista, Prof. Adjunto III - Departamento de Engenharia Rural -FCAV/UNESP, Jaboticabal, SP, email: jepturco@, fcav.unesp.br

2- Engenheira Agrônoma, Doutor em Agronomia (Ciência do Solo)-FCAV/UNESP, Jaboticabal - SP, e-mail: girizzatti@yahoo.com.br 3- Engenheiro Agrônomo, Prof. Doutor- Departamento de Engenharia Rural-FCAV/UNESP, Jaboticabal - SP, e-mail: lcpavani@fcav.unesp.br 


\section{INTRODUÇ̃̃O}

O feijoeiro é uma cultura que assume grande importância sócio-econômica, além de seu produto ser considerado o principal alimento protéico consumido no Brasil. Uma vez que é considerado alimento básico, principalmente da classe populacional de renda mais baixa, tornandose assim um alimento indispensável nas refeições da maioria dos brasileiros (ARF et al., 1996). Segundo Pessoa et al. (2001), o Brasil está entre os três maiores produtores mundiais de feijão, mas, também, é o maior consumidor, necessitando de importações.

Nas regiões onde a insuficiência ou a má distribuição das chuvas, em alguns períodos do ano, inviabiliza a exploração agrícola econômica, a irrigação se justifica como recurso tecnológico indispensável ao aumento da produtividade das culturas, além de contribuir para a utilização mais intensa de recursos produtivos ociosos na propriedade rural (FRIZZONE et al., 1994).

A adoção de técnicas racionais de manejo conservacionista do solo e da água é de fundamental importância para a sustentabilidade dos sistemas agrícolas, de tal forma que se possa, economicamente, manter ao longo do tempo esses recursos com quantidade e qualidade suficientes para a manutenção de níveis satisfatórios de produtividade (WUTKE et al., 2000).

Para o estudo da eficiência do manejo da irrigação, deve-se priorizar o retorno econômico ao irrigante, cuja quantidade de água e época de aplicação é de grande importância para se obter a máxima produção econômica (PAZ et al., 1997).

A irrigação é responsável por grande parte do consumo de energia no meio rural. Normalmente, o produtor rural não adota um método de controle de irrigação; usualmente irriga em excesso, tendo como consequência o desperdício de energia elétrica e de água.

Diante da possibilidade de escassez de energia, aliada à rápida elevação dos custos, procura-se racionalizar o seu uso, utilizando a água de forma mais eficiente. As tarifas de energia são as mais importantes variáveis no custo final da irrigação.

Alves et al. (2003) desenvolveram um trabalho de custo da energia elétrica na irrigação para diferentes regiões brasileiras levando em consideração, tarifas, época do ano e tempo de bombeamento. Recomendam que a tarifa verde e azul com desconto são as melhores opções para o usuário desde que o tempo diário de bombeamento seja de até $21 \mathrm{~h}$, evitando o horário de ponta; caso contrário, recomendam somente a tarifa azul com desconto.

Oliveira et al. (2004), avaliando o desempenho de sistemas de pivô central em onze propriedades na região oeste da Bahia, a partir de indicadores de uniformidade de distribuição de água, adequabilidade da irrigação e eficiência de aplicação de água, concluíram que a uniformidade de aplicação de água variou de 67,6 a 92,4\%, com média de $83 \%$, e que a eficiência em potencial de aplicação de água apresentou, média de 89,5\%, variando de 80 a $99 \%$.

Turco et al. (2009) analisaram o consumo e o custo de energia elétrica em cultura do feijoeiro irrigado por pivô central, cultivar IAC-Carioca, submetida a dois manejos de irrigação e dois sistemas de cultivo em Latossolo Vermelho, no ano de 2002. Concluíram que os tratamentos em que o manejo da irrigação foi realizado pelo método do tanque "Classe A", ocasionaram os maiores consumos e custos de energia elétrica, em relação aos tratamentos em que o manejo foi realizado por tensiometria. Com os sistemas de plantio direto (recém-implantado, 12 meses) e convencional (dentro dos manejos de irrigação), foram observados praticamente os mesmos valores de consumo e de custos com energia elétrica.

LIMA et al. (2009) avaliaram e simularam medidas de eficiência energética em três sistemas pivô central do Assentamento Itamarati I, instalados em Ponta Porã, MS. Os sistemas foram caracterizados quanto ao aproveitamento da energia e a eficiência energética na irrigação média aumentou de 14,9 para $25,9 \%$, possibilitando a redução de R $\$ 118.800$ por ano em 7.200 ha, o equivalente a $11 \%$ das despesas anuais com energia elétrica de toda a propriedade. Concluíram que os projetos de pivôs centrais de irrigação devem contemplar a análise econômica de investimento, não apenas da adutora, mas, também, do motor, da bomba, da linha lateral e dos aspersores.

Objetivou-se, com este trabalho, estudar o

\section{REVENG}

131-141 p. ENGENHARIA NA AGRICULTURA, VIÇOSA - MG, V.20 N.2, MARÇO / ABRIL 2012 
consumo e o custo de energia elétrica e resultado econômico em cultura do feijoeiro irrigado por pivô central, submetida a dois métodos de manejo de irrigação, por tensiometria e pelo balanço hídrico, baseado na diferença entre evapotranspiração estimada pelo método do tanque "Classe A" e a chuva, em sistemas de plantio direto e convencional.

\section{MATERIAL E MÉTODOS}

A pesquisa foi desenvolvida na Área Demonstrativa e Experimental de Irrigação - ADEI, da FCAV/UNESP, Câmpus de Jaboticabal - SP, situada a $21^{\circ} 14^{\prime} 05^{\prime \prime}$ de latitude sul, 48 $17^{\prime} 09^{\prime \prime}$ de longitude oeste e altitude de $613,68 \mathrm{~m}$. O solo da área foi classificado como Latossolo Vermelho eutroférrico (EMBRAPA, 1999).

Os experimentos dos anos estudados (2003 e 2004) foram conduzidos sob um sistema de pivô central, que abrange uma área de $33.157,14 \mathrm{~m}^{2}$. O equipamento possui 30 emissores (difusor fixo, com placa estriada e pendural), igualmente espaçados entre si, distribuídos em duas torres e em um balanço, com um aspersor tipo canhão na extremidade. A uniformidade de aplicação de água e as lâminas médias aplicadas, em diversas velocidades de rotação, foram avaliadas antes da instalação das parcelas experimentais.

A área foi manejada com sucessão das culturas de feijoeiro (cultivar IAC-Carioca) na época mais seca do ano, e de milho, na época mais úmida. A regulagem da semeadora para a cultura do feijoeiro foi para espaçamento de $0,45 \mathrm{~m}$ entre linhas e 18 sementes $\mathrm{m}^{-1}$.

Os tratamentos foram dois métodos de manejo de irrigação e dois sistemas de cultivo, assim descritos: manejo da irrigação por tensiometria (TENS) e pelo balanço hídrico-climatológico baseado no método do tanque "Classe A" (TCA); sistema convencional (PC), em que se realizaram duas gradagens pesadas e uma para destorroamento e incorporação de herbicida pré-plantio (trifluralina), e plantio direto (PD), em que foi aplicado herbicida dessecante antes da semeadura.

Os tratamentos foram assim nomeados:

$\mathrm{T} 1$ = manejo da irrigação por tensiometria e sistema de plantio direto.

$\mathrm{T} 2$ = manejo da irrigação pelo balanço hídricoclimatológico, baseado no método do tanque

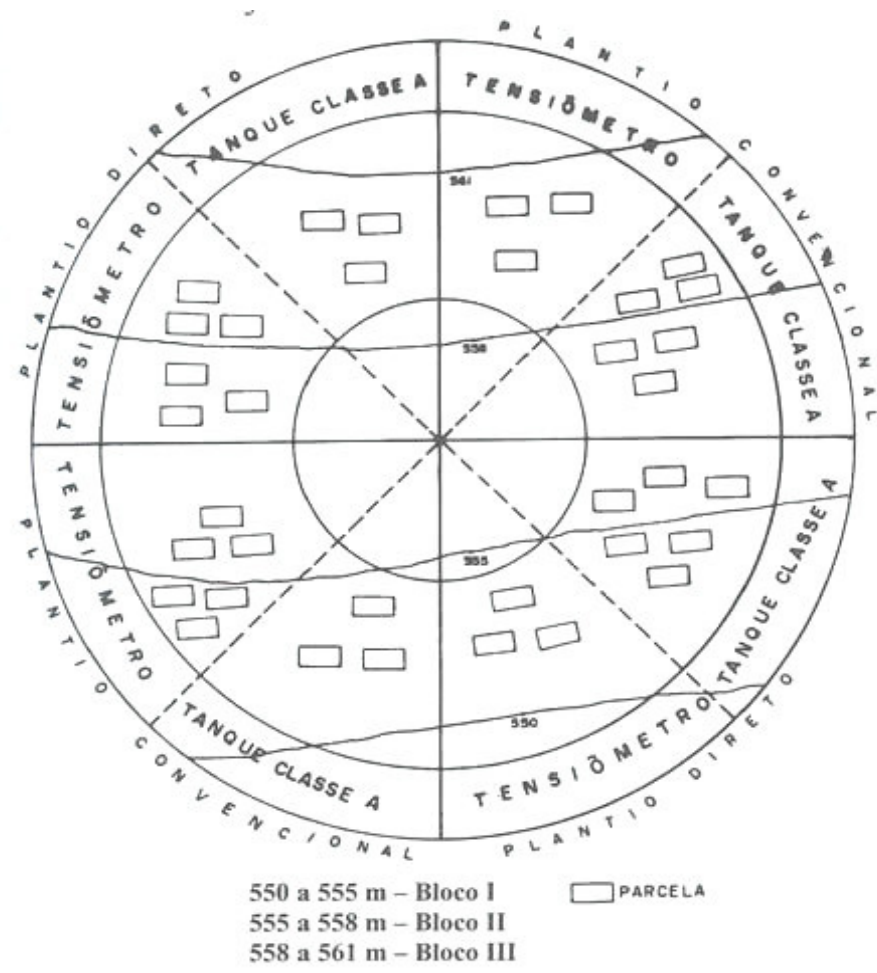

Figura 1. Esquema geral da área experimental. 
"Classe A" e sistema de plantio direto.

$\mathrm{T} 3$ = manejo da irrigação por tensiometria e sistema de plantio convencional.

$\mathrm{T} 4$ = manejo da irrigação pelo balanço hídricoclimatológico, baseado no método do tanque "Classe A" e sistema de plantio convencional.

A área circular abrangida pelo pivô foi dividida em quatro partes, sendo que cada quadrante recebeu um sistema de plantio (PD ou PC), onde o mesmo sistema de plantio corresponde ao quadrante oposto. Cada quadrante foi dividido em octantes, que receberam um manejo de irrigação (TENS ou TCA). A Figura 1 exibe o esquema geral da área experimental, em que cada bloco equivale à cota correspondente, sem escala.

O dia definido como o de irrigação, tanto para TENS quanto para TCA, foi aquele em que a umidade atual do solo (Өa) atingiu valor igual ou menor que o da umidade crítica do solo para a cultura do feijoeiro $(\Theta c)$, cujo valor do potencial mátrico crítico $(\Psi \mathrm{c})$ é de $-40 \mathrm{kPa}$ (SILVEIRA; STONE, 1994). Foi considerado, também, se, no dia previsto ou nos três dias posteriores, a probabilidade de ocorrência de chuva igual ou maior do que a água facilmente disponível no solo (AFD) fosse maior ou igual a $70 \%$.

$\mathrm{AFD}=(\Theta c c-\Theta c) 1.000 \mathrm{Z}$

em que

Өcc $=$ umidade do solo à capacidade de campo para o potencial mátrico de $-10 \mathrm{kPa}, \mathrm{m}^{3} \mathrm{~m}^{-3}$; $\Theta c=$ umidade crítica do solo para a cultura do feijoeiro; e

$\mathrm{Z}=$ profundidade efetiva do sistema radicular da cultura, $0,40 \mathrm{~m}$.

Nas parcelas em que o manejo da irrigação foi efetuado com tensiômetros, os mesmos foram instalados a $0,15 \mathrm{~m}$ e a $0,30 \mathrm{~m}$ de profundidade (SILVEIRA; STONE, 1994), em que o de $0,15 \mathrm{~m}$ foi o de decisão do momento de irrigar, enquanto o de $0,30 \mathrm{~m}$ foi o de controle da profundidade da lâmina aplicada (SAAD; LIBARDI, 1992).

O momento de irrigar foi definido para cada um dos sistemas de cultivo (PC e PD) quando a média entre as leituras dos tensiômetros de decisão, em cada sistema, foi próxima ao valor crítico de potencial mátrico de água no solo $(\Psi \mathrm{c})$. A lâmina de irrigação ou água disponível consumida até o dia da irrigação $\left(\mathrm{ADCi}_{\text {(Tens) }}\right)$, em mm, foi calculada conforme a expressão:

$\mathrm{ADCi}_{\text {(Tens) }}=($ Өcc - Өai $) 1.000 \mathrm{Z}$

em que

ai $=$ umidade atual do solo no momento da irrigação, $\mathrm{m}^{3} \mathrm{~m}^{-3}$; (medida pelo tensiômetro a 15 $\mathrm{cm}$ de profundidade, sendo sua tensão convertida para umidade volumétrica pela curva de retenção do solo.)

A lâmina real aplicada em cada irrigação foi baseada na lâmina média obtida da avaliação do equipamento e na leitura dos pluviômetros instalados no experimento logo após as irrigações.

Para o manejo de irrigação pelo balanço hídrico-climatológico, considerou-se apenas o balanço em 24 horas entre a evapotranspiração da cultura (ETc), estimada pelo método do tanque "Classe A", segundo Allen et al. (1998 a e b), e a chuva total coletada em um pluviômetro tipo "Ville de Paris". O cálculo da lâmina líquida real ou $\mathrm{ADCi}_{(\mathrm{TCA})}$, tomada como referência para lâmina de irrigação a ser aplicada com o pivô central, foi obtido pela seguinte expressão do balanço hídricoclimatológico:

$\mathrm{ADCi}_{(\mathrm{TCA})}=\sum_{\mathrm{ti}}^{\mathrm{tj}}(\mathrm{ETc}-\mathrm{P})$

em que

$\mathrm{ADCi}_{(\mathrm{TCA})} \geq \mathrm{AFD}, 18,16 \mathrm{~mm} ; \mathrm{e}$

(tj-ti) = duração do intervalo em dias, entre duas irrigações.

$\operatorname{AETc}\left(\mathrm{mm} \mathrm{dia}^{-1}\right)$ foi estimada de acordo com a expressão:

$\mathrm{ETc}=\mathrm{ECA} \mathrm{Kp} \mathrm{Kc}$

em que 
$\mathrm{ECA}=$ evaporação medida no tanque "Classe A" $\left(\mathrm{mm} \mathrm{dia}^{-1}\right)$;

$\mathrm{Kp}=$ coeficiente de tanque (adimensional); e

$\mathrm{Kc}=$ coeficiente de cultura (adimensional).

O sistema pivô central utiliza água de um poço artesiano, que possui uma bomba de recalque acoplada a um motor de indução trifásico de 25 $\mathrm{CV}$, que alimenta dois reservatórios d'água. A água dos reservatórios foi recalcada para os aspersores das torres do pivô central por uma bomba d'água acoplada a um motor de indução trifásico de 25 CV. Para a movimentação das duas torres do pivô central, foram utilizados dois motores de $1 / 4 \mathrm{CV}$.

$\mathrm{O}$ consumo de energia elétrica dos quatro motores do sistema de irrigação foi medido por meio da utilização de um medidor de energia (mod. Microvip3 - Elcontrol, Itália).

Foi estudado o custo da energia elétrica para dois grupos tarifários: Grupo A e Grupo B. Para o Grupo A, foram determinados os dispêndios com a energia para a tarifa Estrutura Binômia Convencional e tarifa Horo-Sazonal (verde e/ ou azul). Além da tarifa especial para irrigantes no período noturno (Portaria DNAEE 105 de 0304-92, Resolução ANEEL 277 de 19-07-00, e Resolução ANEEL 540 de 1-10-02).

$\mathrm{O}$ preço da energia elétrica foi obtido junto à Companhia Paulista de Força e Luz - CPFL, e refere-se ao ano de 2006.

O custo do consumo de energia elétrica foi calculado pela seguinte equação:

$\mathrm{CCEE}=\mathrm{CEE} . \mathrm{P}+\mathrm{ICMS}$

em que

$\mathrm{CCEE}=$ custo do consumo de energia elétrica, em R\$; $\mathrm{CEE}=$ consumo de energia elétrica durante qualquer período de tempo, em $\mathrm{kWh}$;

$\mathrm{P}=$ preço do $\mathrm{kWh}$ na estrutura tarifária considerada, em R\$;

ICMS = imposto sobre circulação de mercadorias e serviços;

em que

$$
\mathrm{ICMS}=\frac{\mathrm{I} \cdot \mathrm{A}}{100-\mathrm{A}}
$$

em que

$\mathrm{I}=\mathrm{CEE} . \mathrm{P}$

$\mathrm{A}=$ alíquota, $(18 \%)$.

Foram relacionados o consumo de energia elétrica $(\mathrm{kWh})$ e o custo da energia elétrica $(\mathrm{R} \$)$ com a produtividade obtida nos tratamentos.

A análise econômica foi realizada segundo Martins (2004), em que foi obtido o custo total de produção, que consiste na soma dos custos fixos e variáveis.

Os custos fixos são aqueles que ocorrem independentemente do número de horas anuais de operação do sistema de irrigação e incluem, principalmente, a depreciação do sistema e a remuneração do capital nele investido.

No cálculo da depreciação do sistema, utilizouse o método do fundo de amortização (COELHO, 1979). A depreciação, calculada por tal critério garante que o empresário se servirá dela para substituir o capital, sem utilizar seus recursos particulares ou crédito:

$\mathrm{d}=\frac{(\mathrm{Ci}-\mathrm{Cf}) \mathrm{r}}{(1+\mathrm{r})^{\mathrm{n}}-1}$

em que

$\mathrm{d}=$ quota anual de depreciação, em $\mathrm{R} \$$

$\mathrm{Ci}=$ valor inicial do sistema, em $\mathrm{R} \$$;

$\mathrm{Cf}=$ valor final ou residual do sistema, em $\mathrm{R} \$$;

$\mathrm{r}=$ taxa anual de juros, em decimal; e

$\mathrm{n}=$ vida útil do sistema, em anos.

O preço médio do pivô-central, com as dimensões consideradas no projeto foi pesquisado no mercado, sendo de $\mathrm{R} \$ 44.154,40$, para o ano de 2006.

O valor dos juros sobre o capital investido significa que o empresário renunciou à remuneração que poderia ter obtido pela aplicação de seus capitais em alternativas. Essa renúncia representa, para o empresário, o custo a ser considerado. Para seu cálculo, adota-se, a rigor, o valor do equipamento usado; quando não se conhece tal valor, Neves e Shirota (1986) recomendam trabalhar com uma 
estimativa representada pela média do valor novo:

$\mathrm{JSC}=\frac{(\text { Ci.r })}{2}$

A soma dos juros sobre o capital com a depreciação resulta no custo fixo anual do sistema de irrigação.

No cálculo dos custos variáveis da irrigação, estão envolvidos os custos de manutenção, mãode-obra e energia. Assumiu-se que os custos de manutenção e mão-de-obra para os diferentes tratamentos foram iguais. Assim, os custos variáveis considerados neste trabalho, referem-se apenas aos dispêndios com a energia.

$\mathrm{O}$ resultado econômico foi obtido subtraindo-se a receita da produtividade do feijão do custo total de produção do feijão, para cada ano estudado.

\section{RESULTADOS E DISCUSSÃO}

O consumo de energia ativa por hectare e a produtividade em $\mathrm{kg}$. ha ${ }^{-1}$, para os quatro tratamentos, são ilustrados na Figura 2, para o ano 2003, e na Figura 3, para o ano de 2004. A produtividade média de grãos é analisada no Quadro 1, para o ano de 2003, e no Quadro 2, para o ano de 2004.

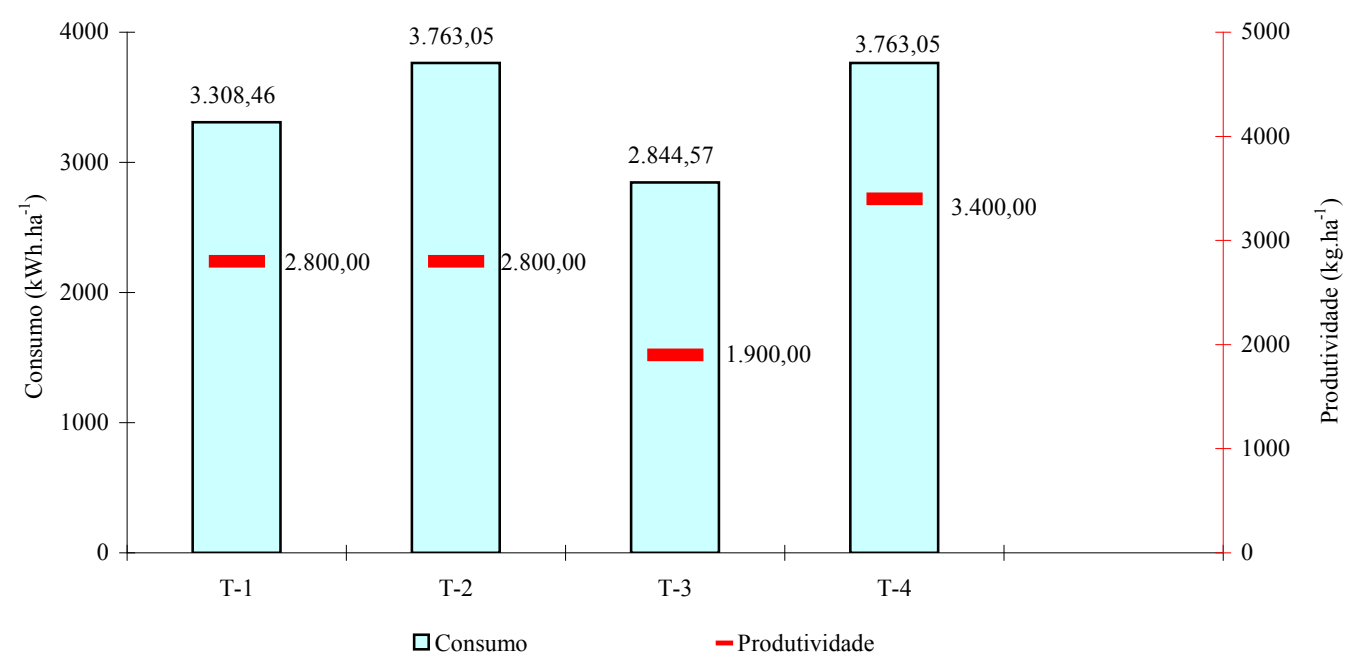

Figura 2. Consumo de energia elétrica ativa, e produtividade de grãos, para o ano de 2003 [Tratamentos: T-1 (TENS + PD), T-2 (TCA + PD), T-3 (TENS + PC) e T-4 (TCA + PC)].

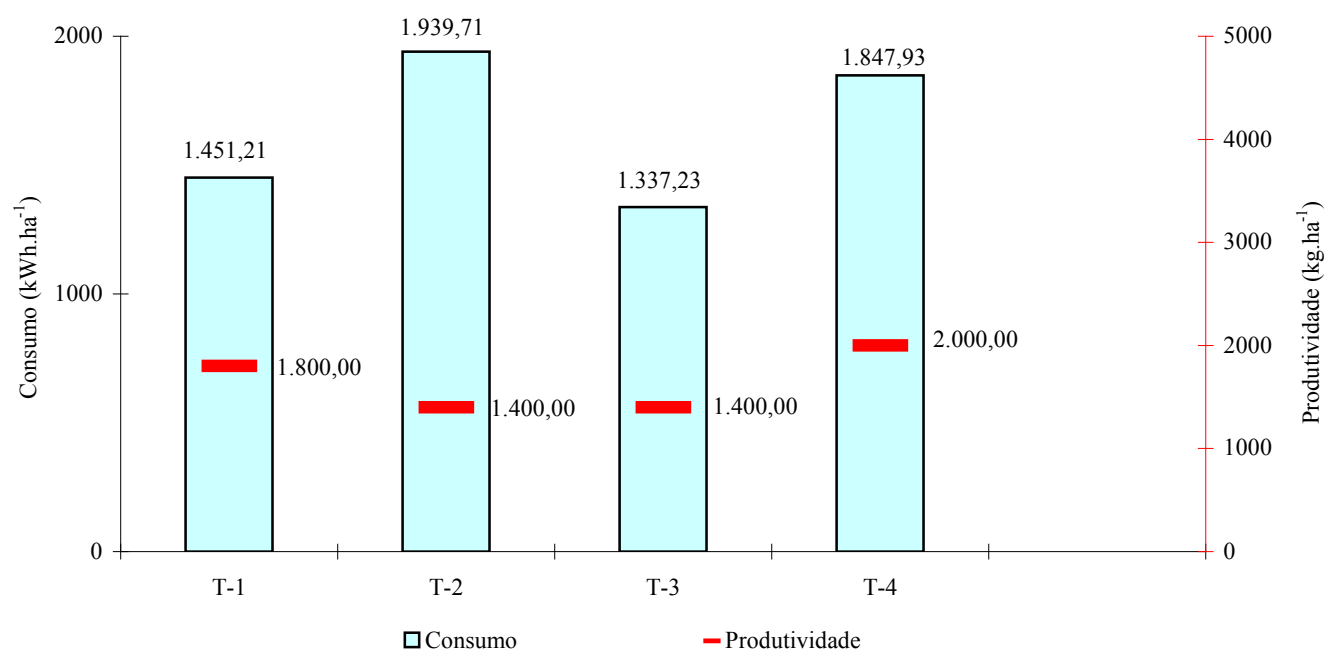

Figura 3. Consumo de energia elétrica ativa, e produtividade de grãos, para o ano de 2004 [Tratamentos: T-1 (TENS + PD), T-2 (TCA + PD), T-3 (TENS + PC) e T-4 (TCA + PC)]. 
Quadro 1. Produtividade média de grãos $\left(\mathrm{kg} \cdot \mathrm{ha}^{-1}\right)$, no ano de 2003

\begin{tabular}{ccc}
\hline Sistemas de cultivo & \multicolumn{2}{c}{ Manejo da irrigação } \\
\hline & Tensiômetro & Tanque "Classe A" \\
\cline { 2 - 3 } Plantio convencional & $1900 \mathrm{Bb}$ & $3400 \mathrm{Aa}$ \\
Plantio direto & $2800 \mathrm{Aa}$ & $2800 \mathrm{Ba}$ \\
\hline
\end{tabular}

Médias seguidas de letras distintas, maiúsculas nas colunas e minúsculas nas linhas, diferem entre si pelo teste de Tukey $(\mathrm{P}<0,05)$.

Quadro 2. Produtividade média de grãos $\left(\mathrm{kg} \cdot \mathrm{ha}^{-1}\right)$, no ano de 2004

\begin{tabular}{ccc}
\hline Sistemas de cultivo & Manejo da irrigação & \\
\hline & Tensiômetro & Tanque "Classe A" \\
\cline { 2 - 3 } Plantio convencional & $1400 \mathrm{Ab}$ & $2000 \mathrm{Aa}$ \\
Plantio direto & $1800 \mathrm{Aa}$ & $1400 \mathrm{Ba}$ \\
\hline
\end{tabular}

Médias seguidas de letras distintas, maiúsculas nas colunas e minúsculas nas linhas, diferem entre si pelo teste de Tukey $(\mathrm{P}<0,05)$.

Quadro 3. Estimativa do custo do consumo de energia elétrica (CCEE), para o Grupo B, nos anos de 2003 e 2004 (preço do $\mathrm{kWh}=\mathrm{R} \$ 0,17634$ )

\begin{tabular}{ccc}
\hline TRATAMENTOS & CCEE $\left(\mathrm{R} \$ \cdot\right.$ ha $\left.^{-1}\right)-$ Ano: 2003 & CCEE $\left(\right.$ R $\$ \cdot$ ha $\left.^{-1}\right)-$ Ano: 2004 \\
\hline T1 $($ TENS + PD $)$ & 711,48 & 312,61 \\
T2 (TCA + PD) & 809,24 & 417,84 \\
T3 (TENS + PC) & 611,72 & 288,06 \\
T4 (TCA + PC) & 809,24 & 398,07 \\
\hline
\end{tabular}

Pode-se observar, na Figura 2, que no ano de 2003 o consumo de energia elétrica foi maior nos tratamentos 2 e 4 , nos quais o manejo da irrigação foi baseado no tanque "Classe A" seguido pelo 1 e 3, nos quais o manejo de irrigação foi realizado por tensiometria. Pela aplicação do teste de Tukey (5\%) (Quadro 1), pode-se afirmar que no manejo por tensiometria, o tratamento 1 (PD) obteve melhor produtividade que o tratamento 3 (PC), e que no manejo pelo tanque "Classe A" o tratamento $4(\mathrm{PC})$ obteve melhor produtividade que o tratamento 2 (PD). No sistema de cultivo plantio convencional o tratamento 4 (TCA) obteve melhor produtividade que o tratamento 3 (TENS), já no sistema de plantio direto não houve diferença significativa entre os tratamentos 1 (TENS) e 2 (TCA).

No ano de 2004 (Figura 3), o consumo de energia elétrica foi maior nos tratamentos 2 e 4 , nos quais o manejo da irrigação foi baseado no tanque "Classe A" seguido pelos tratamentos 1 e 3 , nos quais o manejo de irrigação foi realizado por tensiometria. O consumo de energia elétrica, dentro dos manejos de irrigação, para os sistemas de plantio direto e convencional, são semelhantes. Pela aplicação do teste de Tukey (5\%), (Quadro 2 ), pode-se afirmar que no manejo pelo tanque "Classe A" o tratamento 4 (PC) obteve melhor produtividade que o tratamento 2 (PD), já no manejo por tensiometria não houve diferença significativa entre os tratamentos 1 (PD) e 3 (PC). No sistema de cultivo plantio convencional o tratamento 4 (TCA) obteve melhor produtividade que o tratamento 3 (TENS), já no sistema de plantio direto não houve diferença significativa entre os tratamentos 1 (TENS) e 2 (TCA).

Turco et al. (2009) mostraram que os tratamentos em que o manejo da irrigação foi realizado pelo método do tanque "Classe A" ocasionaram os maiores consumos e custos de energia elétrica. Assim, estes resultados corroboram com os deste trabalho.

Os valores do custo de energia elétrica para o sistema tarifário grupo $\mathrm{B}$, para os tratamentos estudados estão apresentados no Quadro 3, para os anos de 2003 e 2004. 
Observa-se que no ano de 2003, os tratamentos 2 e 4, em que o manejo foi realizado pelo método do tanque "Classe A", obtiveram os maiores custos de energia elétrica, sendo o tratamento 4 o de maior produção; já os tratamentos 1 e 3 , em que o manejo foi realizado por tensiometria obtiveram os menores custos de energia elétrica, porém menores produções. Comparando-se os sistemas de plantio direto e convencional, dentro dos manejos de irrigação, nota-se que T4 e T2 apresentaram os mesmos valores de custo de energia elétrica, já T1 apresentou valor superior a T3, porém obteve maior produtividade.

No ano de 2004, os tratamentos 2 e 4, em que o manejo foi realizado utilizando-se o método do tanque "Classe A" proporcionaram os maiores custos de energia elétrica, e os tratamentos 1 e 3 , em que o manejo foi realizado por tensiometria proporcionaram os menores custos de energia elétrica. Comparandose os sistemas de plantio direto e convencional, dentro dos manejos de irrigação, nota-se que estes apresentaram praticamente os mesmos valores de custo de energia elétrica.

$\mathrm{O}$ sistema tarifário grupo $\mathrm{B}$, normalmente é aplicado a propriedades rurais que possuem transformadores instalados de até 112,5 kVA. O fato de o agricultor possuir esse transformador, não impede que ele faça opção por outros sistemas tarifários, junto a CPFL.

As tarifas Horo-Sazonais permitem ao consumidor irrigante reduzir suas despesas com energia elétrica, desde que ele consiga programar o seu uso. Essa redução poderá ser obtida evitando-se o horário de ponta e/ou deslocando-se o consumo para determinados meses do ano.

Considerou-se a tarifa vigente Horo-Sazonal Verde e/ou Azul com o valor de 21,60 KW para a demanda fora de ponta (preço da demanda 7,90 R $\$ \mathrm{KW}^{-1}$ ). No Quadro 4 são apresentados os resultados para o sistema tarifário citado, com desconto especial para irrigantes no período noturno, para os anos de 2003 e 2004.

Nota-se, com base nos dados apresentados no Quadro 4 que a tarifa Horo-Sazonal Verde e/ou Azul com desconto especial para irrigantes no período noturno é uma opção mais adequada para a cultura do feijoeiro, em relação ao sistema tarifário Grupo B, concordando com Alves et al. (2003), pois diminuiu o gasto com energia elétrica, para todos os tratamentos, nos anos estudados, resultando, portanto, maior retorno econômico ao irrigante.

Foram calculados a depreciação anual do sistema (Eq. 8) e os juros sobre o capital (Eq. 9) e posteriormente somados, resultando no custo fixo anual do sistema de irrigação (Quadro 5).

Neste trabalho, verificou-se que a tarifa HoroSazonal Verde e/ou Azul, com desconto especial para irrigantes no período noturno, foi a opção mais adequada para a cultura do feijoeiro nos anos estudados; os custos variáveis considerados são os custos dos consumos de energia elétrica para este sistema tarifário (Quadro 6).

A soma dos custos fixos de produção com os custos variáveis de produção (CCEE) resulta no custo total de produção (Quadro 7).

As produtividades em sacas.ha ${ }^{-1}$, são apresentadas no Quadro 8.

Quadro 4. Estimativa do custo do consumo de energia elétrica (CCEE), para o Grupo A - Estrutura HoroSazonal Verde e/ou Azul, com desconto, para os anos de 2003 e 2004 (preço do $\mathrm{kWh}=\mathrm{R} \$ 0,16650$ )

\begin{tabular}{ccc}
\hline TRATAMENTOS & CCEE $\left(\mathrm{R} \$ \cdot \mathrm{ha}^{-1}\right)-$ Ano: 2003 & CCEE $\left(\mathrm{R} \$ . \mathrm{ha}^{-1}\right)-$ Ano: 2004 \\
\hline T1 $($ TENS + PD) & 252,73 & 139,59 \\
T2 (TCA + PD) & 280,42 & 169,35 \\
T3 (TENS + PC) & 224,47 & 132,65 \\
T4 (TCA + PC) & 280,42 & 163,76 \\
\hline
\end{tabular}

Quadro 5. Preço do sistema, depreciação anual, juros sobre o capital investido (JSC), custos fixos anuais e por hectare, para uma taxa de juros de $12 \%$ ao ano, vida útil do sistema de 10 anos e valor residual do sistema igual a zero

\begin{tabular}{ccccc}
\hline $\begin{array}{c}\text { Preço do pivô } \\
\text { Total }(\mathrm{R} \$)\end{array}$ & $\begin{array}{c}\text { Depreciação } \\
\mathrm{R} \$ \cdot \text { ano }^{-1}\end{array}$ & $\begin{array}{c}\text { JSC } \\
\mathrm{R} \$ \cdot \mathrm{ano}^{-1}\end{array}$ & $\begin{array}{c}\text { Custos Fixos } \\
\mathrm{R} \$ \cdot \mathrm{ano}^{-1}\end{array}$ & $\begin{array}{c}\text { Custos Fixos } \\
\mathrm{R} \$ . \mathrm{ha}^{-1}\end{array}$ \\
\hline $44.154,40$ & $2.516,10$ & $2.649,26$ & $5.165,36$ & $1.557,84$ \\
\hline
\end{tabular}


Considerando-se a saca de feijão de $60 \mathrm{~kg}$, com valor igual a $\mathrm{R} \$ 70,00$ (preço médio pesquisado), obtém-se a receita, em $\mathrm{R} \$$ ha $^{-1}$ (Quadro 9).

O resultado econômico foi obtido subtraindose a receita da produtividade do feijão, pelo custo total de produção do feijão, para cada ano estudado (Quadro 10).

Pela análise do Quadro 10, percebe-se que, no ano de 2003, o maior retorno econômico foi obtido por T4, seguido por T1, T2 e T3; o sistema de plantio direto, tanto no manejo por tensiometria, quanto no manejo pelo tanque "Classe A", obteve praticamente o mesmo resultado econômico, já o sistema de plantio convencional, obteve o melhor resultado econômico, quando o manejo de irrigação foi efetuado pelo tanque "Classe A". Em 2004, os melhores resultados econômicos foram obtidos em $\mathrm{T} 4$ e $\mathrm{T} 1$, sendo que em T2 e T3, os resultados econômicos foram negativos, indicando que as receitas não cobriram os custos finais de produção.

Observou-se uma tendência, de maior retorno econômico, para o tratamento 4, onde o manejo de irrigação foi realizado pelo tanque "Classe A", e o sistema de plantio adotado foi o convencional, para os dois anos estudados.

Quadro 6. Custos variáveis de produção (CCEE), em R $\$$. ha $^{-1}$

\begin{tabular}{ccc}
\hline TRATAMENTOS & 2003 & 2004 \\
\hline T1 (TENS + PD) & 252,73 & 139,59 \\
T2 (TCA + PD) & 280,42 & 169,35 \\
T3 (TENS + PC) & 224,47 & 132,65 \\
T4 (TCA + PC) & 280,42 & 163,76 \\
\hline
\end{tabular}

Quadro 7. Custo total de produção (custos fixos + custos variáveis (CCEE)), em R $\$$.ha ${ }^{-1}$

\begin{tabular}{ccc}
\hline TRATAMENTOS & 2003 & 2004 \\
\hline T1 (TENS + PD) & $1.810,57$ & $1.697,43$ \\
T2 (TCA + PD) & $1.838,26$ & $1.727,19$ \\
T3 (TENS + PC) & $1.782,31$ & $1.690,49$ \\
T4 (TCA + PC) & $1.838,26$ & $1.721,60$ \\
\hline
\end{tabular}

Quadro 8. Produtividades do feijão, em sacas.ha ${ }^{-1}$

\begin{tabular}{ccc}
\hline TRATAMENTOS & 2003 & 2004 \\
\hline T1 (TENS + PD) & 46,67 & 30,00 \\
T2 (TCA + PD) & 46,67 & 23,33 \\
T3 (TENS + PC) & 31,67 & 23,33 \\
T4 (TCA + PC) & 56,67 & 33,33 \\
\hline
\end{tabular}

Quadro 9. Receita da produtividade de feijão para os anos estudados. (R\$.ha $\left.{ }^{-1}\right)$

\begin{tabular}{ccc}
\hline TRATAMENTOS & 2003 & 2004 \\
\hline T1 $($ TENS + PD) & $3.266,67$ & $2.100,00$ \\
T2 (TCA + PD) & $3.266,67$ & $1.633,33$ \\
T3 (TENS + PC) & $2.216,67$ & $1.633,33$ \\
T4 (TCA + PC) & $3.966,67$ & $2.333,33$ \\
\hline
\end{tabular}

Quadro 10. Resultado econômico $\left(\mathrm{R} \$ . \mathrm{ha}^{-1}\right)$

\begin{tabular}{ccc}
\hline TRATAMENTOS & 2003 & 2004 \\
\hline T1 $($ TENS + PD) & $1.456,09$ & 402,57 \\
T2 (TCA + PD) & $1.428,40$ & $-93,86$ \\
T3 (TENS + PC) & 434,35 & $-57,16$ \\
T4 (TCA + PC) & $2.128,40$ & 611,73 \\
\hline
\end{tabular}




\section{CONCLUSÕES}

- Os tratamentos em que o manejo da irrigação foi realizado pelo método do Tanque "Classe A", devido ao maior consumo de água observado, obtiveram os maiores consumos e custos de energia elétrica, em relação aos tratamentos em que o manejo foi realizado por tensiometria, nos dois anos estudados.

- Os sistemas de plantio direto e convencional (dentro dos manejos de irrigação) apresentaram praticamente os mesmos valores de consumo e custo de energia elétrica, para os anos estudados.

- A tarifa Horo-Sazonal Verde e/ou Azul com desconto especial para irrigantes no período noturno foi a opção mais adequada para a cultura do feijoeiro, para todos os tratamentos, nos dois anos estudados; e

- O maior retorno econômico foi para o tratamento em que o manejo de irrigação foi realizado pelo tanque "Classe A", e o sistema de plantio adotado foi o convencional, para os dois anos estudados.

\section{REFERÊNCIAS BIBLIOGRÁFICAS}

ALLEN, R. G.; PEREIRA, L. S.; RAES, D.; SMITH, M. Pan evaporation method. In:

Crop evopotranspiration. Roma: FAO, 1998a. p.78-85 (Irrigation and Drainage, 56).

ALLEN, R. G.; PEREIRA, L. S.; RAES, D.; SMITH, $\mathrm{M}$. Etc- single crop coefficiente $(\mathrm{Kc})$ In:

Crop evopotranspiration. Roma: FAO, 1998b p.103-34 (Irrigation and Drainage, 56).

ALVES, J.; FIGUEREDO, L. G. M.; COELHO, R.; ZOCOLER, J. L. Custo da energia elétrica na irrigação. In: Congresso Brasileiro de Engenharia Agrícola, 32, 2003, Goiânia. Anais... Goiânia: SBEA, 2003.

ARF, O.; SÁ, M. E.; OKITA, C. S.; TIBA, M. A.; GUERREIRO NETO, G.; OGASSAWARA, F. Y. Efeito de diferentes espaçamentos e densidades de semeadura sobre o desenvolvimento do feijoeiro
(Phaseolus vulgaris L.). Pesquisa Agropecuária Brasileira, Brasília, v.31, n.8, p.533-597, set, 1996.

COELHO, S. T. Matemática financeira e análise de investimentos. 1. ed. São Paulo: Ed. Nacional; EDUSP, 1979. 279p.

EMPRESA BRASILEIRA DE PESQUISA AGROPECUÁRIA - EMBRAPA. Sistema brasileiro de classificação de solos. 1. ed. Rio de Janeiro, Ministério da Agricultura e do Abastecimento, 1999. 412p.

FRIZZONE, J. A., BOTREL, T. A., FREITAS, H. A. C. Análise comparativa dos custos de irrigação por pivô central, em cultura de feijão, utilizando energia elétrica e óleo diesel. Engenharia Rural, Piracicaba, v. 5, n.1, p.34-53, jul, 1994.

LIMA, A. C.; GUIMARÃES JÚNIOR, S. C.; FIETZ, C. R; CAMACHO, J. R. Avaliação e análise da eficiência energética na irrigação em sistemas pivô central. Rev. bras. eng. agríc. Ambient, Campina Grande, v.13, n.4, p.499-505, jul/ago, 2009.

MARTINS, M. I. E. G. Custo de produçãao. Apostila. Jaboticabal: FCAV, 2004. 23p.

NEVES, E. M.; SHIROTA, R. Considerações sobre a importância, determinação e atualização dos custos agrícolas; programa de treinamento BANESPA. Piracicaba: FEALQ, 1986. 23p.

OLIVEIRA, A. S.; PEREIRA, F. A. C.; PAZ, V. P. S. Avaliação do desempenho de sistemas de pivô central na região oeste da Bahia. Irriga, Botucatu, v.9, n.2, p.126-135, mai/ago, 2004.

PAZ, V. P. S.; FRIZZONE, J. A.; BOTREL, T. A.; FOLEGATTI, M. V. Redução na receita líquida por déficit ou excesso de água na cultura do feijoeiro. Pesquisa Agropecuária Brasileira, Brasília, v.32, n.9, p.869-875, set, 1997.

PESSOA, P. C. S., MENDONÇA, F. C., SILVA, F. C. Redução do custo operacional de irrigação e uniformização de aplicação de água em pivô 
central. In: Congresso Brasileiro de Engenharia Agrícola, 30., 2001, Foz de Iguaçu. Anais... Foz de Iguaçu: SBEA, 2001. 1 CD ROM.

SAAD, A. M.; LIBARD, P. L. Uso prático do tensiômetro pelo agricultor irrigante. 1 . ed. São Paulo: IPT, 1992. 27p.

SILVEIRA, P. M.; STONE, L. F. Manejo da irrigação do feijoeiro: uso do tensiômetro e avaliação do desempeno do pivô central. Goiânia: EMBRAPA, 1994. 46p. (Circular Técnica, 27).
WUTKE, E. B.;ARRUDA, F. B.;FANCELLI,A. L.; PEREIRA, J. C. V. N. A.; SAKAI, E.; FUJIWARA, M.; AMBRosAnO, G. M. B. Propriedades do solo e sistema radicular do feijoeiro irrigado em rotação de culturas. Revista Brasileira de Ciência do Solo, Viçosa, v.24, n.3, p.621-33, 2000.

TURCO, J. E. P.; RIZZATTI, G. S.; PAVANI, L. C. Custo de energia elétrica em cultura do feijoeiro irrigado por pivô central, afetado pelo manejo da irrigação e sistemas de cultivo. Engenharia Agrícola, Jaboticabal, v.29, n.2, p.311-320, abr/jun, 2009. 